cardiovascular side effects at the Massachusetts General Hospital, Boston, MA. Treatment with tricyclic antidepressants (TCA) caused small increases in blood pressure and heart rate, and lengthening of PR, QRS, and QT conduction parameters on the ECG. Imipramine may be associated with lower rates of sinus tachycardia and intraventricular conduction lengthening than other TCAs, and desipramine may have the greatest tendency to cause QT prolongation. ECG abnormalities were related to the dose and relatively higher serum TCA levels. ECG monitoring is recommended with doses of TCAs of $2.5 \mathrm{mg} / \mathrm{kg}$ day $(1 \mathrm{mg} / \mathrm{kg}$ day for nortryptyline), and doses more than $5 \mathrm{mg} / \mathrm{kg}$ day should be avoided. Lightheadedness or headaches signal the need for a check of vital signs, ECG, and TCA serum levels. Guidelines for monitoring ECG and vital signs in children receiving TCAs are suggested. (Wilens TE, Biederman J, Baldessarini $\mathrm{RJ}$ et al. Cardiovascular effects of therapeutic doses of tricyclic antidepressants in children and adolescents. I Am Acad Child Adolesc Psychiatry Nov 1996;35:1491-1501). (Reprints: Dr Wilens, ACC 725, Massachusetts General Hospital, Boston, MA 02114).

COMMENT. Tricyclic antidepressants are a second-line choice of medication for ADHD, sometimes favored in children with psychiatric comorbidity or enuresis. Although in general the cardiovascular effects are minor, tachycardia and shortness of breath, and occasional reports of idiosyncratic fatalities in TCA-treated children are a concern to some practitioners. Without frequent ECG monitoring, it is likely that these cardiovascular abnormalities and associated symptoms are often unrecognized. Children engaged in sporting activities especially should be closely examined for cardiac related side effects, and alternative treatments substituted.

Protriptyline for ADHD. Side effects were particularly prominent in a trial of protriptyline in 13 children with ADHD, and less than $50 \%$ showed a positive response. (Wilens TE, Biederman J, Abrantes AM, Spencer TJ. A naturalistic assessment of protriptyline for attention-deficit hyperactivity disorder. I Am Acad Child Adolesc Psychiatry Nov 1996;35:1485-1490).

\title{
SEASON OF BIRTH: A RISK FACTOR FOR ADHD
}

Seasonal variations in the birth patterns of 140 ADHD boys compared to 120 controls were studied at the Massachusetts General Hospital, Boston, with particular reference to issues of psychiatric and cognitive comorbidity and familiality. Statistically significant peaks for September births were noted in ADHD children with comorbid learning disabilities and in those without psychiatric comorbidity. A trend toward an increase in winter births was also evident. A first-trimester viral hypothesis for ADHD is suggested. (Mick E, Biederman J, Faraone SV. Is season of birth a risk factor for attention-deficit hyperactivity disorder? IAm Acad Child Adolesc Psychiatry Nov 1996;35:14701476). (Reprints: Dr Biederman, Pediatric Psychopharmacology Unit (ACC 725), Massachusetts General Hospital, Fruit Street, Boston, MA 02114).

COMMENT. Exposure to viral infections during winter months in the first trimester of fetal life or at the time of birth may be a predisposing factor in $10 \%$ of ADHD subjects having comorbid learning disabilities. Prenatal or perinatal infection as a possible cause of ADHD requires further evaluation.

Familial transmission of ADHD is supported by a prospective fouryear follow-up study of siblings of ADHD children, one fourth having developed ADHD and one half showing evidence of school failure. (Faraone SV, Biederman J et al. I Am Acad Child Adolesc Psychiatry Nov 1996;35:1449-1459). 